\title{
A valoração em metapoemas de Manuel Bandeira: universal ou absoluto?
}

\author{
Dayane Celestino de ALMEIDA \\ (Universidade de São Paulo / PIBIC-CNPq)
}

RESUMO: No âmbito da semiótica dita tensiva, os valores de universo resultam na valorização da participação, da expansão, do numeroso, e são regidos pelas operações de mistura e abertura; os de absoluto dizem respeito a uma valorização do raro, do exclusivo, do puro, e são regidos pelas operações de triagem e fechamento. Nosso objetivo é identificar quais valores propõem os metapoemas estudados.

PALAVRAS-CHAVE: semiótica literária; valoração; tensividade; poesia brasileira

RÉSUMÉ: Dans le cadre de la sémiotique dite tensive, les valeurs d'univers ont pour résultat la valorisation de la participation, de l'expansion, du nombreux, et résultent des opérations de mélange et d'ouverture. Les valeurs d'absolu, elles, aboutissent à la valorisation du rare, voire de l'exclusif et du pur, manifestant les opérations de tri et de fermeture. La présente étude se propose de mettre en évidence les valeurs présentées sous cet aspect par les poèmes analysés.

MOTS-CLÉS: sémiotique littéraire; valorisation; tensivité; poésie brésilienne 


\section{INTRODUÇão}

Ao longo de sua carreira, Manuel Bandeira escreveu vários poemas que podem ser considerados "poéticas", ou seja, eles tratam do "fazer poesia", ora dizendo para que a poesia serve, ora dizendo como ela é ou deve ser. Este trabalho lida com dois destes metapoemas - "Poética", do livro Libertinagem, de 1930, e "Nova poética", do livro Belo Belo, de 1948 - e o aspecto que aborda é a relação entre intensidade, extensidade e valoração em tais textos.

Segundo Fontanille e Zilberberg (2001), os universos de valores são regidos no espaço tensivo pelas valências de intensidade e extensidade. Na ordem da extensidade, são dois os grandes tipos de valores polares: os valores de universo (ou universal) e os valores de absoluto. Segundo Lopes (2005:206) "A extensidade mostra-se na tensão contínua entre o uno e o múltiplo". Assim, quanto mais se caminha em direção ao "mais", ao numeroso, mais próximo se está dos valores de universo e, ao contrário, quanto mais se vai em direção ao "menos", ao uno, mais próximo se está dos valores de absoluto. A figura a seguir representa esta relação:

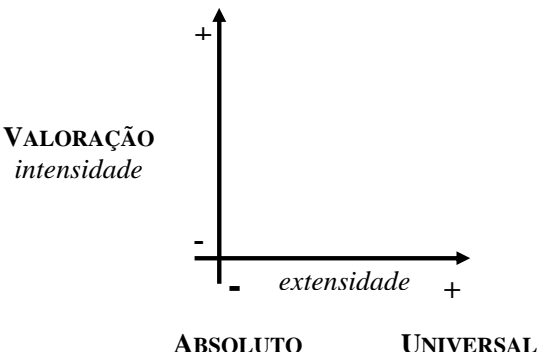

Os valores de universo estão relacionados à valorização da participação, da expansão, do numeroso e são regidos pelas operações de mistura e abertura; já os valores de absoluto dizem respeito a uma valorização do raro, do exclusivo, do puro, e são regidos pelas operações de triagem e fechamento, como podemos verificar no quadro-resumo abaixo:

\begin{tabular}{|c|c|c|}
\hline Regime & Valores de absoluto & Valores de universo \\
\hline Operadores & Triagem/Fechamento & Participação \\
\hline Valoração & $\begin{array}{c}\text { Valorizaração do raro, do } \\
\text { puro, do exclusivo. }\end{array}$ & $\begin{array}{c}\text { Valorização da } \\
\text { participação, da } \\
\text { expansão, do } \\
\text { numeroso, do } \\
\text { "misturado". }\end{array}$ \\
\hline
\end{tabular}


A partir das considerações acima, temos como objetivo identificar em qual destes dois regimes está assentado cada um dos poemas analisados, ou seja, procuramos verificar que valores propõem esses metapoemas.

\section{VALORES EM "PoÉTICA"}

Iniciemos nossa análise por "Poética". Este é um poema que expressa como a poesia deveria ou não-deveria ser, bastante paralelo aos preceitos modernistas. Dentre os poemas de Bandeira que podem ser considerados uma ars poetica, talvez este seja o mais conhecido e aclamado. Quanto a isto, citamos o crítico Ivan Junqueira que afirma:

"Poética" não é apenas um dos melhores poemas do autor, mas também um dos mais importantes que escreveu, talvez o mais significativo no que se refere ao discurso metalingüístico e à síntese de seus procedimentos líricos (2003:107).

O poema foi publicado em 1930 no livro Libertinagem, que o próprio Bandeira reconheceu ser, dentre seus livros, aquele que mais se enquadra na técnica e estética do modernismo. Em "Poética" há uma negação da poesia tradicional e a afirmação de um lirismo "livre". A poesia deve ser livre das formas preestabelecidas, das palavras empertigadas, dos modelos tradicionais e livre para falar de qualquer tema. "Poética" soa como um grito de libertação. Grito que perpassa todo o livro Libertinagem, desde seu título, pois libertinagem aqui não tem o significado associado à "prática do libertino", mas sim, a uma "irreverência com relação a dogmas e crenças oficialmente aceitos"1, uma vez que o próprio Bandeira, ao comentar o seu livro anterior ( $O$ ritmo dissoluto), afirma que nele alcançou uma "completa liberdade de movimentos" e complementa: "liberdade de que cheguei a abusar no livro seguinte, a que por isso mesmo chamei Libertinagem" (1984:75). Ou, como disse Ribeiro Couto: "libertinagem de temas, de matéria. Total liberdade" (apud Junqueira, 2003:89). Ao comentar Libertinagem na sua História concisa da literatura brasileira, Alfredo Bosi afirma que o livro apresenta "um fortíssimo anseio de liberdade vital e estética" (2006:363).

Vejamos a transcrição do poema:

\section{POÉTICA}

Estou farto do lirismo comedido

Do lirismo bem comportado

Do lirismo funcionário público com livro de ponto expediente protocolo e [manifestações de apreço ao sr. diretor

Estou farto do lirismo que pára e vai averiguar no dicionário o cunho verná[culo de um vocábulo

Abaixo os puristas

Todas as palavras sobretudo os barbarismos universais

Todas as construções sobretudo as sintaxes de exceção

Todos os ritmos sobretudo os inumeráveis 
Estou farto do lirismo namorador

\section{Político}

Raquítico

Sifilítico

De todo lirismo que capitula ao que quer que seja fora de si mesmo.

De resto não é lirismo

Será contabilidade tabela de co-senos secretário do amante exemplar com [cem modelos de cartas e as diferentes [maneiras de agradar às mulheres, etc.

Quero antes o lirismo dos loucos

O lirismo dos bêbedos

O lirismo difícil e pungente dos bêbedos

O lirismo dos clowns de Shakespeare

— Não quero mais saber do lirismo que não é libertação.

Constatamos que a poesia valorizada - o "lirismo livre" - está associada ao regime da participação, que tem por operador a mistura - valorizando, assim, uma poética mais diversificada - em oposição à valorização da poesia "tradicional" do raro, do puro, associada ao regime da exclusão. Há determinadas passagens do poema que corroboram essa afirmação, conforme podemos resumir no quadro que segue:

\section{$\Rightarrow$ "Poética":}

\begin{tabular}{|c|c|c|}
\hline & VALORES DE ABSOLUTO & VALORES DE UNIVERSO \\
\hline Regime & Exclusão & Participação \\
\hline Operadores & Triagem/Fechamento & Mistura/Abertura \\
\hline $\begin{array}{l}\text { “Tipo" de } \\
\text { poética }\end{array}$ & $\begin{array}{c}\text { Poética "tradicional” } \\
\text { Valorização do raro, do puro }\end{array}$ & $\begin{array}{c}\text { Poética "modernista" } \\
\text { Valorização de uma poética } \\
\text { mais livre e diversificada }\end{array}$ \\
\hline $\begin{array}{l}\text { Passagens } \\
\text { do texto }\end{array}$ & $\begin{array}{l}\text { • v.1: "lirismo comedido" } \\
\text { • v.2: "lirismo comportado" } \\
\text { • v.3: "lirismo funcionário } \\
\text { público" } \\
\text { • v.4: "lirismo que pára" } \\
\text { • v.5: "abaixo os puristas" }\end{array}$ & $\begin{array}{l}\text { • v. 6: "Todas as palavras" } \\
\text { • v. 7: "Todas as } \\
\text { construções" } \\
\text { • v. 8: "Todos os ritmos" } \\
\text { • v.16: "lirismo dos } \\
\text { bêbedos" } \\
\text { • v.17: "lirismo pungente" } \\
\text { • v.18: "lirismo dos clowns } \\
\text { de Shakespeare" }\end{array}$ \\
\hline
\end{tabular}


Constatamos, portanto, que o poema nega os valores de absoluto relacionados à "poesia tradicional" - e afirma os valores de universo - relacionados à "poesia modernista". As figuras abaixo exemplificam estas relações:

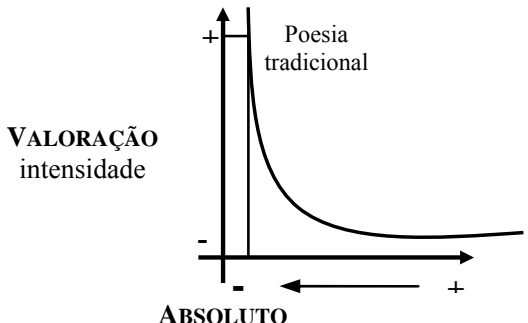

extensidade

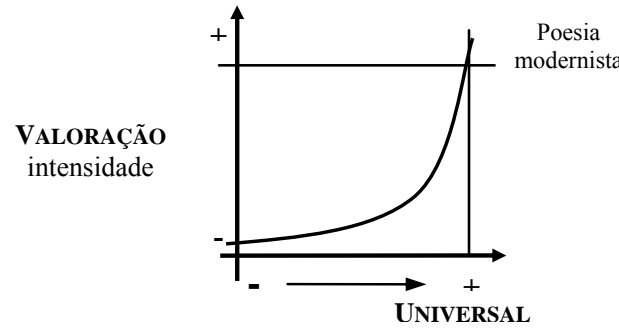

extensidade

Um ponto interessante a destacar é o fato de que apesar de este "eu" professar uma lógica da inclusão, da heterogeneidade ("Todas as palavras", "Todas as construções", "Todos os ritmos", o lirismo "livre"), suas "reivindicações" encontram-se dentro de uma lógica da triagem, no que se refere aos lirismos a serem descartados, excluídos (lirismo comedido, lirismo raquítico, lirismo namorador etc.). Ou seja, para carregar a bandeira de uma poética que admite a participação, que admite a mistura, ele permanece no regime da exclusão, ao excluir o exclusivo.

Tal fato vai ao encontro do que dizem Fontanille e Zilberberg. Segundo estes autores:

a perspectiva adotada, a partir da alternativa entre valores de absoluto e valores de universo, vai afetar o discurso e funcionar, ela própria, como uma instância de triagem, deixando passar as configurações discursivas que estão de acordo com o ponto de vista adotado e barrando as que pertencem ao outro regime de valores (Fontanille \& Zilberberg, 2001:48).

Assim, mesmo para obter uma mistura, é necessário fazer uma triagem, para, como já mencionamos, "excluir o exclusivo".

Voltando um pouco à questão que comentamos anteriormente sobre "Poética" reivindicar uma poesia mais livre, há ainda algumas considerações a fazer. O lirismo livre - a poesia que admite todas as palavras, todas as construções, todos os ritmos - é muito valorizado, enquanto o outro lirismo ganha um estatuto de não-lirismo, conforme o verso 14: "de resto não é lirismo".

Deste modo, podemos fazer uma representação da seguinte maneira: inserimos no eixo da extensidade o parâmetro "liberdade formal e temática" (que vai do menos livre ao mais livre). Podemos estabelecer uma relação conversa entre intensidade e extensidade, uma vez que quanto maior for a liberdade, maior será a valoração, 
configurando o lirismo "verdadeiro" e quanto menor a liberdade, menor vai ser o valor configurando-se aí o não lirismo. Vejamos a figura abaixo:

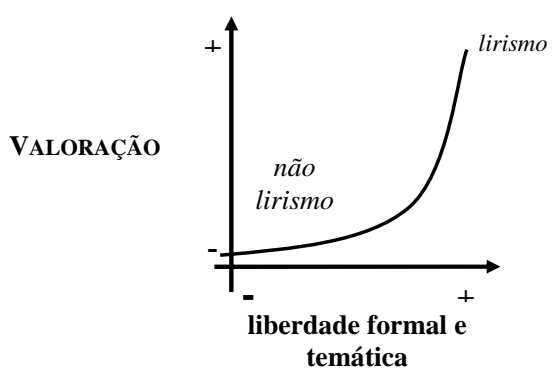

\section{VALORES EM “NOVA POÉTICA”}

Dezenove anos após a publicação de "Poética" - o poema que "se celebrizou como um manifesto modernista em versos" (Moura, 2001:52) - Manuel Bandeira escreve "Nova poética", integrante do livro Belo Belo. Sétimo livro de poemas do autor, Belo Belo foi publicado em 1948 como parte de uma nova edição do livro Poesias completas. Sendo "Nova poética" - conforme podemos ler na datação junto ao poema - do ano de 1949 , supomos que sua inclusão em Belo Belo foi feita posteriormente, no momento de uma nova edição ${ }^{2}$. Vejamos, a seguir, a transcrição do poema:

\section{NOVA POÉTICA}

Vou lançar a teoria do poeta sórdido.

Poeta sórdido:

Aquele em cuja poesia há a marca suja da vida.

Vai um sujeito.

Sai um sujeito de casa com a roupa de brim branco muito bem engomada, e [na primeira esquina passa um caminhão, salpica-lhe

É a vida. [o paletó ou a calça de uma nódoa de lama:

O poema deve ser como a nódoa no brim:

Fazer o leitor satisfeito de si dar o desespero.

Sei que a poesia é também orvalho.

Mas este fica para as menininhas, as estrelas alfas, as virgens cem por cento e [as amadas que envelheceram sem maldade.

19 de maio de 1949 
A análise do poema leva-nos a concluir que o texto também valoriza uma poética da mistura - de valores de universo, revelados no nível discursivo pelo tema da "sujeira" e pelas figuras: "nódoa" e "lama" e "suja" (que "mancham", que "se misturam") - em oposição a uma lógica da triagem, uma vez que o poema nega o absoluto, o puro, representado no nível discursivo pelas figuras do "branco" e do "orvalho". Lembremos, ainda, que "as menininhas", "as virgens cem por cento" e "as amadas sem maldade" são também figuras que remetem à pureza e são disforizadas no texto.

Desta maneira, para o enunciador de "Nova poética", quanto mais a poesia estiver em conformidade com os valores de universo, maior a sua valoração, ou seja, quanto mais se avança em direção ao "mais" (ao universal) no eixo da extensidade, maior é o valor (no eixo da intensidade), que é exatamente o que ocorreu em "Poética".

Num texto intitulado "As condições semióticas da mestiçagem", Zilberberg (2004) diz que "a dimensão da intensidade tem, como intervalo de referência, [impactante vs fraco]" e "a dimensão da extensidade tem, como intervalo de referência (...) [puro vs impuro]".

Ora, conforme o verso 8, o poema deve "Fazer o leitor satisfeito de si dar o desespero", isto é, deve causar um impacto no leitor. Percebemos, assim, que "Nova poética" propõe uma poesia que seja impactante, e ao mesmo, tempo "impura", heterogênea, sórdida. O gráfico a seguir demonstra bem esta correlação:

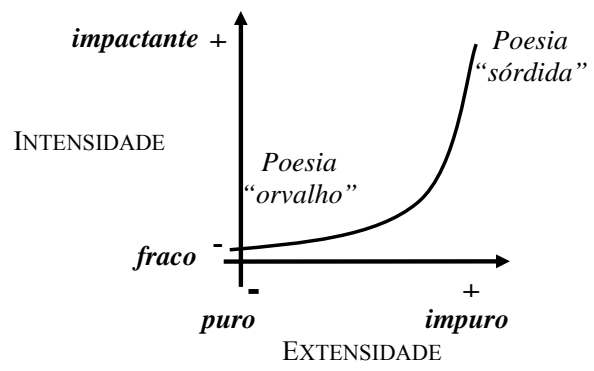

Observamos que uma oposição entre uma poética do presente e outra do passado é estabelecida, sendo a poesia do presente a poesia "sórdida", e a do passado a "poesia orvalho". Isto pode ser afirmado uma vez que a escolha da palavra "orvalho" não é aleatória, pois o orvalho é uma figura muito recorrente nos poemas românticos e simbolistas. Concluímos que esse poema, que lança "a teoria do poeta sórdido", vem ratificar a proposta poética que Bandeira vinha delineando havia trinta anos, ou seja, desde a publicação de "Os sapos", em 1919 (Carnaval), que não apresentamos detalhadamente nesta ocasião, mas que também propõe uma poética de acordo com os valores de universo. 


\section{CONSIDERAÇõES FINAIS}

Verificamos que os poemas analisados se colocam como uma ars poetica, indicando como a poesia deveria ou não deveria ser. Ambos são uma espécie de manifesto que nega a poesia de períodos anteriores, propondo um modo novo de se fazer poesia. Com relação aos sistemas de valores, averiguamos que os dois textos negam os valores de absoluto - relacionados à "poesia tradicional", à poesia de períodos anteriores - indo ao encontro dos valores de universo - relacionados à "poesia modernista" e "pósmodernista". Observado atentamente, percebemos que estes valores ligados à mistura estão presentes em toda a obra de Manuel Bandeira, uma vez que o autor, mesmo com uma produção poética bastante alinhada ao Modernismo nos anos de maior força do movimento, não pode ser enquadrado em uma escola literária específica, dada à heterogeneidade de sua obra. Assim, conforme Arrigucci:

Desde o princípio, Bandeira parece aberto ao que der e vier: ele imita, pasticha, plagia, parodia, traduz, cita ou incorpora, se este é o caso, sem nenhum receio, sem discriminar a natureza ou o nível da fonte, sem se escravizar às receitas (tradicionais primeiro ou, mais tarde, modernistas), adotando uma completa independência de espírito diante da norma estética e uma total falta de pudor diante da heterogeneidade dos materiais e dos meios técnicos, o que constitui precisamente o fundamento de sua atitude técnica, no seu sentido mais geral, em face da obra a ser feita (Arrigucci Jr., 2003:139).

Heterogênea, a poesia de Bandeira perpassa vários momentos da poesia brasileira, fazendo eco a importantes movimentos estéticos, como o Simbolismo e o Parnasianismo, cujas características estão muito presentes nos primeiros livros (principalmente em A cinza das horas, 1917), ou o Modernismo, refletido com toda a sua força, por exemplo, em Libertinagem (1930). Bandeira experimenta, ainda, o sabor da poesia concreta e tem uma significativa produção em prosa e em crítica literária. Sobre essa diversidade de estilos, Rosenbaum afirma:

O estudo da obra de Manuel Bandeira impõe-nos, de imediato, um espaço configurado por várias vertentes estilísticas: parnasianismo, simbolismo, penumbrismo, as vanguardas européias e o modernismo brasileiro (Rosenbaum, 2002:23).

Concluímos que a obra bandeiriana é, como dizia o próprio Bandeira, sobre "tudo", indo dos "amores" aos "chinelos", das "coisas lógicas" às "mais disparatadas" (Bandeira, 1984:19), sendo, pois, nos termos da semiótica, da ordem valorização da participação, da expansão, do misturado, ou seja, inclui-se no regime dos valores de universo.

\section{NOTAS}

${ }^{1}$ Conforme o dicionário Houaiss.

${ }^{2}$ No Itinerário de Pasárgada, ao comentar o livro Belo Belo, Bandeira afirma: "Na edição de 51 acrescentei mais quatorze poemas..." (1984:124). 


\section{REFERÊNCIAS BIBLIOGRÁFICAS}

ARRIGUCCI JR., Davi. Humildade, paixão e morte: a poesia de Manuel Bandeira. São Paulo: Cia. das Letras, 2003.

BANDEIRA, Manuel. Poesias completas. Rio de Janeiro: Livraria-Editora da Casa do Estudante do Brasil, 1951.

BANDEIRA, Manuel. Itinerário de Pasárgada. Rio de Janeiro: Nova Fronteira, 1984. . Estrela da vida inteira. Rio de Janeiro: Nova Fronteira, 1993.

BOSI, Alfredo. História concisa da literatura brasileira. São Paulo: Cultrix, 2006.

FONTANILLE, Jacques \& ZILBERBERG, Claude. Tensão e significação. Tradução de Ivã Carlos Lopes; Luiz Tatit; Waldir Beividas. São Paulo: Discurso Editorial/Humanitas, 2001.

JUNQUEIRA, Ivan. Testamento de Pasárgada. Rio de Janeiro: Nova Fronteira, 2003.

LOPES, Ivã Carlos; HERNANDES, Nilton (orgs.). Semiótica: objetos e práticas. São Paulo: Contexto, 2005.

MOURA, Murilo Marcondes. Manuel Bandeira. São Paulo: Publifolha, 2001.

ROSENBAUM, Yudith. Manuel Bandeira: uma poesia da ausência. São Paulo: Edusp, 2002.

ZILBERBERG, Claude. “As condições semióticas da mestiçagem”. In: CAÑIZAL, Eduardo Peñuela \& CAETANO, Kati (orgs.). O olhar à deriva: mídia, significação e cultura. Tradução de Ivã Lopes; Luiz Tatit. São Paulo: Annablume, 2004.

\section{Como citar este artigo:}

ALMEIDA, Dayane Celestino de. A valoração em metapoemas de Manuel Bandeira: universal ou absoluto? Estudos Semióticos.

[online] Disponível na Internet via WWW.URL: http://www.fflch.usp.br/dl/semiotica/es. Editor Peter Dietrich. Número 4, São Paulo, 2008.

Acesso em "dia/mês/ano". 